\title{
O Os Jovens que não Estudam nem Trabalham no Brasil: Uma Análise do Perfil, Determinantes da Condição e Efeitos do Programa Bolsa Familia
}




\section{Resumo}

O PRESENTE ARTIGO INVESTIGA OS JOVENS OUEE NÃO ESTUDAM NEM TRABALHAM (NEET) NO BRASIL usando dados da Pesou usa nacional por Amostra de Domicílios (PNAD) No Período 20012012. APRESENTA UMA ANÁLISE CRÍTICA DO CONCEITO DE NEET, SITUA O BRASIL NO CONTEXTO INTERNACIONAL, TRAÇA A TENDÊNCIA NA ÚLTIMA DÉCADA E O PERFIL DESSES JOVENS. ESTIMA VARIAÇÕES NA PROBABILIDADE DE O JOVEM ESTAR NA CONDIÇÃO DE NEET EM FUNÇÃO DA PARTICIPAÇÃO NO PROGRAMA BoLSA FAMÍLIA (BF) E IDENTIFICA ALGUNS DOS FATORES OUUE AFETAM AOQUELA PROBABILIDADE. No CASO DAS MULHERES, MAIORIA DOS JOVENS NEET,

A PRESENÇA DE FILHOS DE O A 3 ANOS E O CASAMENTO (ALÉM DO NÍVEL DE RENDA E DA ESCOLARIDADE) APARECEM COMO FORTES DETERMINANTES DO STATUS DE NEET. ESSE STATUS PARA AS MULHERES É UMA CONDIÇÃO DE LONGO PRAZO NÃO SENDO, PORTANTO, UMA CONDIÇÃO DE "SER JOVEM", MAS DE SER MULHER EM CONDIÇÕES DE POUCA IGUALDADE NA RELAÇÃO DE GÊNERO. CONCLUI-SE OQUE O FENÔMENO NO BRASIL TEM CARACTERÍSTICAS ESPECÍFICAS OUE SUGEREM UM DESENHO DE POLÍTICA OQUE COMBINE PREFERENCIALMENTE SUPORTE DE RENDA ÀS JOVENS MÃES E ACESSO A SERVIÇOS DE CRECHE E PRÉ-ESCOLA. O CONTEXTO BRASILEIRO SE DIFERENCIA DAOUELE DOS PAÍSES DA OCDE, ONDE A CRISE DO EMPREGO É CENTRAL. AOUI, AS DESIGUALDADES SOCIAIS FORTEMENTE MARCADAS PELA DIFERENÇA DE RENDA DAS FAMÍLIAS E DO ACESSO AOS SERVIÇOS DE EDUCAÇÃO INFANTIL, ASSOCIADA À DESIGUALDADE DE GÊNERO, ASSUMEM MAIOR IMPORTÂNCIA NA CRIAÇÃO DO FENÔMENO DOS NEETS.

\section{Abstract}

THIS PAPER INVESTIGATES THE YOUTHS NEITHER IN EMPLOYMENT NOR IN EDUCATION OR TRAINING (NEET) IN BRAZIL USING DATA fRom the National Household Sample SuRVEy (PNAD) IN THE PERIOD 2001-2012. IT PRESENTS A CRITICAL ANALYSIS OF THE VERY CONCEPT OF NEET, SITUATES BRAZIL WITHIN THE INTERNATIONAL CONTEXT, AND OUTLINES THE LAST DECADE TREND AS WELL AS THESE YOUTHS' PROFILES. VARIATIONS IN THE LIKELIHOOD OF A YOUTH TO BE FOUND AS NEET ARE ESTIMATED AS A FUNCTION OF HIS/HER PARTICIPATION IN THE BOLSA FAMÍLIA PROGRAMME (BF) AND SOME OF THE FACTORS THAT AFFECTS THAT LIKELIHOOD ARE ALSO IDENTIFIED. IN THE CASE OF WOMEN, THE MAJORITY OF NEETS IN BRAZIL, HAVING CHILDREN AGED O TO 3 AND BEING MARRIED (BESIDES FAMILY INCOME AND EDUCATION ATTAINMENT) STANDS OUT AS TWO MAJOR DETERMINANTS OF THE NEET STATUS. TO BE IN THE NEET POSITION IS A LONG-TERM CONDITION FOR WOMEN, THEREFORE NOT BEING JUST A "YOUTH" CONDITION BUT INSTEAD A "FEMALE" CONDITION MARKED BY INEQUALITIES BETWEEN GENDERS. IN CONCLUSION, THE NEET PHENOMENON IN BRAZIL HAS PARTICULAR FEATURES SUGGESTING THAT AN OPTIMAL POLICY SHOULD COMBINE INCOME SUPPORT TO THE YOUNG MOTHERS IN TANDEM WITH ACCESS TO CHILD CARE. IN THIS SENSE, BRAZILIAN CONTEXT DIFFERS FROM OECD COUNTRIES WHERE HIGH LEVEL OF UNEMPLOYMENT IS A MAJOR PROBLEM. HERE, SOCIAL INEQUALITIES DUE TO DIFFERENCES IN FAMILY INCOME AND ACCESS TO CHILD CARE COMBINED WITH GENDER DIFFERENCES PLAY A CENTRAL ROLE IN CREATING THE NEET PHENOMENON.

\section{PALAVRAS-CHAVE:}

Juventude, Nem-Nem, Bolsa Família, Educação e Trabalho, Mulheres

Revista Brasileira de Monitoramento e Avaliação | Número 6 | Julho-Dezembro de 2013

Os Jovens que não estudam nem trabalham no Brasil: uma análise do perfil, determinantes da condição e efeitos do Programa Bolsa Familia 
1. Os jovens que não trabalham nem estudam ("nem-nem")um conceito e suas dificuldades

O fenômeno" de jovens que se encontram fora da escola e do mercado de trabalho, e não participam de nenhuma forma de programa de treinamento para o trabalho - grupo representado pela sigla em inglês "NEET" (neither in employment nor in education or trainning) - foi identificado pela primeira vez em meados da década de 1990. No contexto da América Latina, esse grupo é referido pela expressão "ni-ni" - do espanhol ni estudan ni trabajan - sendo no Brasil chamado de "nem-nem" ${ }^{\prime 2}$. Sendo um conceito apenas recentemente incorporado ao debate público e às políticas públicas, algumas dificuldades ainda persistem.

A primeira dificuldade é o recorte de "jovem" considerado no grupo dos NEET. Oual a faixa etária referida pelo termo "jovem"? A Organização para a Cooperação e Desenvolvimento Econômico (OCDE), por exemplo, utiliza a faixa de 15 a 29 anos em suas estatísticas de NEET. ${ }^{3}$ No Reino Unido, o foco de atenção recai sobre os jovens entre 16 e 19 anos de idade; ${ }^{4}$ no Japão, o termo se refere aos "jovens" de 15 a 34 anos que não estão no mercado de trabalho, são solteiros, não estão em instituições de ensino nem ocupados em afazeres domésticos. ${ }^{5}$ Nos Estados Unidos, como no Brasil, é comum as estatísticas se referirem à faixa etária de 16 a 24 anos; faixa em que do jovem no Brasil é esperado ter concluído o Ensino Fundamental e estar no Ensino em que da grande maioria dos jovens espera-se que realize a transição escola-trabalho. A definição do grupo etário no qual o problema é diagnosticado importa na medida em que comparações internacionais tomam lugar e políticas públicas focalizadas são desenhadas para mitigar o problema.

A segunda dificuldade é a definição de NEET, ou seja, quem é considerado nessa condição. Por exemplo, aqueles jovens que não estudam nem trabalham, mas estão disponíveis para o mercado de trabalho (uma vez que buscam trabalho ativamente), devem ser incluídos? E quanto àqueles que não estudam nem trabalham por estarem tomando conta de filhos, pessoas idosas ou doentes? Outros ainda, no caso das mulheres, dedicam-se apenas a afazeres domésticos ${ }^{6}$ ou se retiram temporariamente do mercado de trabalho ou do sistema educacional por estarem em período de gestação. Há ainda os que se dedicam ao desenvolvimento de talentos artísticos ou esportivos que não envolvem, pelo menos por algum tempo, vínculos com os sistemas formais de educação e o mercado de trabalho. Há jovens que podem ser encontrados engajados em atividades de caráter filantrópico em entidades religiosas, organizações civis; ou de natureza política, em partidos políticos, movimentos sociais, associações de bairros etc. Há ainda o caso dos que estariam em fase de transição entre escola e trabalho, durante a qual receberiam apoio dos pais sem que 
estejam engajados em atividades laborais ou educativas formais (e.g. viagens de intercâmbio cultural, temporada com parentes em outra cidade/país, voluntariado). É possível também que alguns desses jovens estejam se preparando para exames de acesso ao nível superior sem que estejam frequentando uma unidade de ensino.

Esses exemplos mostram que há situações de não vínculo ao mercado de trabalho ou ao sistema formal de educação como medidos pelas pesquisas domiciliares que, no entanto, não caracterizaram ociosidade ou inatividade do jovem que pudesse ser objeto de preocupação do Poder Público. Pelo contrário, representam formas de engajamento social diversas, formativas e que contribuem para o fortalecimento do tecido social. Há também pessoas com deficiências físicas ou doenças incapacitantes para o trabalho que devem ser assistidas pelos sistemas de proteção social e saúde e que podem permanecer temporariamente ou permanentemente fora mercado de trabalho e do sistema educacional. Há, por outro lado, situações dos jovens que, estando fora do mercado de trabalho e do sistema educacional, podem estar sob o risco de (ou já engajados em) atividades socialmente indesejáveis como organizações criminosas e abuso de drogas; ou simplesmente vivendo em ociosidade não produtiva, com baixo nível de expectativas, podendo cair em depressão e desencanto com seu próprio futuro.

É necessário, portanto, considerar que sob o rótulo genérico de NEET existem situações muito diversas, caso se queira tomar esse grupo como foco de políticas para a juventude. A identificação a priori como um gru-

2 Neste trabalho uso a sigla NEET conforme o termo em inglês.

$3($ OECD, 2012)

4 (Maguire, 2008; Finlay et al., 2010).

5 (Pemberton, 2008)

6 Estima-se que na América Latina 22\% das jovens entre 15 e 29 anos se dedicam exclusivamente a afazeres domésticos, representando uma parcela significativa dos jovens classificados como NEET. Esta cifra é de apena 1,4\% entre os jovens do sexo masculino (Hopenhayn, 2012).

Revista Brasileira de Monitoramento e Avaliação | Número 6 | Julho-Dezembro de 2013 
po problemático que conote uma condição socialmente negativa pode significar uma simplificação grosseira daquilo que caracteriza o real motivo de se encontrarem fora da escola e do mercado de trabalho. Além disso, sem que se considere como os próprios jovens avaliam e se sentem na condição que os gestores de políticas e acadêmicos vêm chamando de NEET, pode levar a uma estigmatização que só venha a agravar o sentimento de isolamento e não pertencimento social do jovem. Pesquisas qualitativas conduzidas no Japão, Taiwan e Reino Unido mostram como se pode estar distante da realidade ao interpretarmos o jovem sob a perspectiva estreita da função produtiva que, se não o localiza na escola formal ou no mercado de trabalho, já o enquadra na condição de risco social. ${ }^{7}$ Como as fontes de dados usadas para analisar o fenômeno em geral não contêm informação sobre atividades do jovem fora do mercado laboral ou educacional (inclusive a PNAD no Brasil), a real inserção social do jovem é de difícil avaliação no nível agregado, havendo necessidade de conduzir pesquisas qualitativas que ajudem a entender melhor sua situação.

A terceira dificuldade envolve o elemento temporal, ou seja, por quanto tempo deve o jovem estar na situação de NEET para que este seja assim classificado. A vida do jovem tende a ser mais dinâmica, com mudanças mais frequentes em sua situação ocupacional. Desse modo, as medidas efetuadas num instante de tempo (como no caso da PNAD, no Brasil) capturam uma situação que pode já ser diferente no dia, semana ou mês seguinte, tendo ela mesma durado apenas alguns dias, meses ou eventualmente anos. É importante definir o horizonte de tempo na classificação do jovem no grupo NEET. Incorporar o horizonte temporal na própria definição de NEET é uma saída que evitaria a inclusão no grupo de casos cuja inatividade tivesse duração pequena ou sazonal, que não exigiriam maior atenção do Poder Público.

A quarta dificuldade refere-se ao aspecto da escolha. Está o jovem inativo por opção ou por circunstâncias alheias à sua vontade? Há casos em que fatores institucionais ou estruturais jogam um peso maior na definição da situação do jovem, que exerce pouco ou nenhum controle sobre esses fatores. Fatores institucionais incluem, por exemplo: a forma de organização do sistema educacional, seus mecanismos de exclusão e as trajetórias possíveis que oferece ao jovem durante a sua vida escolar; os mecanismos de transição escola-trabalho e o suporte ao jovem na escolha profissional e na busca de emprego; a organização do mercado de trabalho e os incentivos existentes para a contratação dos jovens. Fatores estruturais como a origem social do jovem, seu local de moradia, o status econômico de sua família, raça e gênero se combinam com os fatores institucionais na determinação das circunstâncias que levam o jovem a "optar" ou "cair" na inatividade. É sobre os fatores institucionais que as políticas públicas devem atuar, sendo focalizadas a partir dos grupos sociais mais afetados pelo problema. Os fatores estruturais da desigualdade mencionados devem servir como parâmetros de identificação daqueles grupos.

Há, por outro lado, a dimensão da escolha, ou seja, o jovem pode, num dado momento, 
optar de fato por estar simultaneamente fora da escola e do trabalho (por exemplo, dedicando-se a uma das atividades mencionadas em parágrafo anterior), ainda que essa escolha se dê no contexto de suas circunstâncias e seja em algum grau por elas determinada. As motivações ou razões que levam o jovem a se encontrar no grupo NEET são diversas e desafiam os formuladores de políticas que precisam considerar essa diversidade na proposição de programas com foco nesse grupo.

Essas dificuldades colocam um desafio para a política pública ao considerar o grupo NEET como um grupo homogêneo. O risco aqui é propor soluções para lidar com os jovens NEET como um grupo ignorando os indivíduos, em que todos possam ser tratados com a mesma intervenção a partir de um mesmo diagnóstico (potencialmente errado) do problema. Por trás do rótulo classificatório de NEET existem histórias muito diferentes, envolvendo características, circunstâncias e comportamentos que diferenciam os jovens para além da classificação de NEET. ${ }^{8}$ O diagnóstico deve ser mais cuidadoso e evitar simplificações redutoras. A política pública deve buscar se aproximar das situações reais e se apresentar como um espaço de oportunidades para respostas individuais às necessidades e desafios que se coloquem a cada jovem em particular.

\section{O Brasil no contexto internacional}

Longe de ser levantado como um problema apenas dos países em desenvolvimento, os NEETs vêm despertando a atenção em todo o mundo, principalmente a partir da crise financeira internacional de 2008, que trouxe recessão econômica e, com ela, o agravamento da situação de desemprego, em particular nos países desenvolvidos. A Organização para a Cooperação Econômica e o Desenvolvimento (OCDE) estima que, dois anos após o início da crise (2010), a taxa de jovens desempregados ou inativos entre 15 e 29 anos de idade, e que também não estavam na escola, já atingia 15,8\% nos países da OCDE, alcançando o maior índice na Turquia (36,6\%), em Israel (27,4\%), no México $(24,4 \%)$ e na Espanha $(23,7 \%)$. Entre os 21 países analisados na União Europeia, a média no mesmo ano foi de $14,8 \%$. O Brasil, se examinado utilizando o mesmo conceito de NEET da OCDE ${ }^{9}$, aparece com 19,6\% (Figura 1).

9 Jovens de 15 a 29 anos de idade fora da escola que estão desempregados ou inativos.

Revista Brasileira de Monitoramento e Avaliação | Número 6 | Julho-Dezembro de 2013 
FIGURA 1: TAXA DE NEETS NA POP. 15-29 (INCLUINDO PEA) PAÍSES DA OCDE E BRASIL 2010

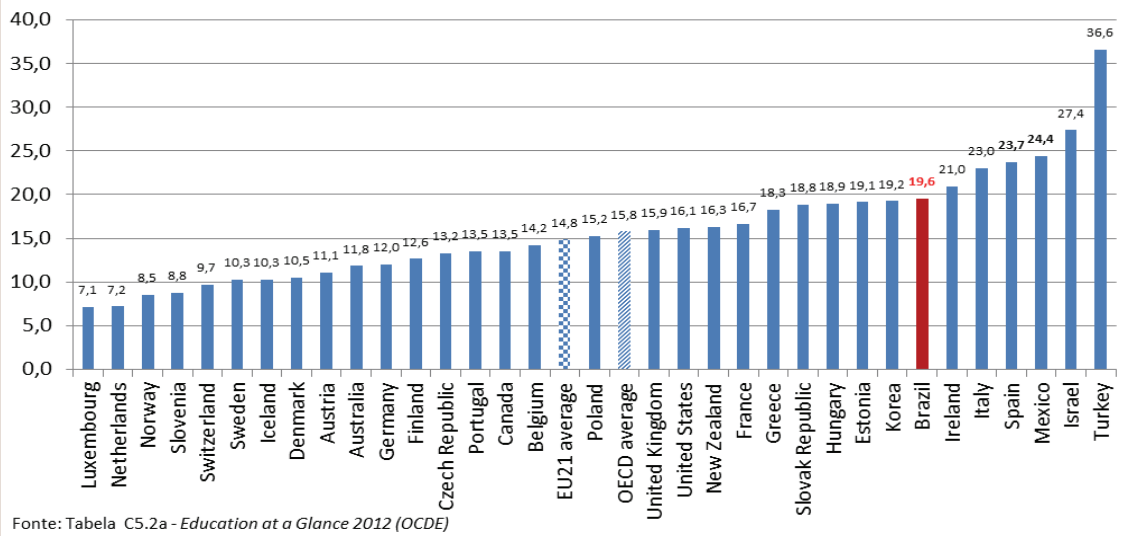

O problema em conjugar sob a mesma categoria de NEET os jovens desempregados e os inativos é que, possivelmente, os primeiros serão mais facilmente reintegrados pelos mecanismos de mercado na medida em que o nível de emprego cresça na economia, enquanto os segundos não necessariamente. Por exemplo, se observarmos a posição da Espanha no ranque de países quando consideramos na categoria de NEET apenas os jovens que estão fora da escola e inativos, ou seja, não trabalham e não procuram trabalho (Figura 2), vemos que a alta taxa de desemprego naquele país faz aumentar o percentual de NEETs de $7,4 \%$ para $23,7 \%$.
Ou seja, dentre os $23,7 \%$ de jovens classificados como NEETs na Espanha na Figura 1, $7,4 \%$ são inativos e $16,4 \%$, desempregados. Se tomarmos o caso do México, cuja taxa de NEETs na Figura 1 alcança a cifra de 24,4\%, próxima à da Espanha, a situação é inversa, ou seja, 20,4\% são inativos enquanto apenas $4 \%$ são desempregados. No caso espanhol, o percentual de NEETs tende a cair significativamente se a economia retomar o crescimento e o nível de emprego aumentar. O mesmo não se pode esperar no caso do México. Trata-se, portanto, de duas situações distintas que requerem medidas de política diferentes. 


\section{- FIGURA 2: TAXA DE NEETS NA POP. 15-29 (Ñ-PEA) PAÍSES DA OCDE E BRASIL 2010}

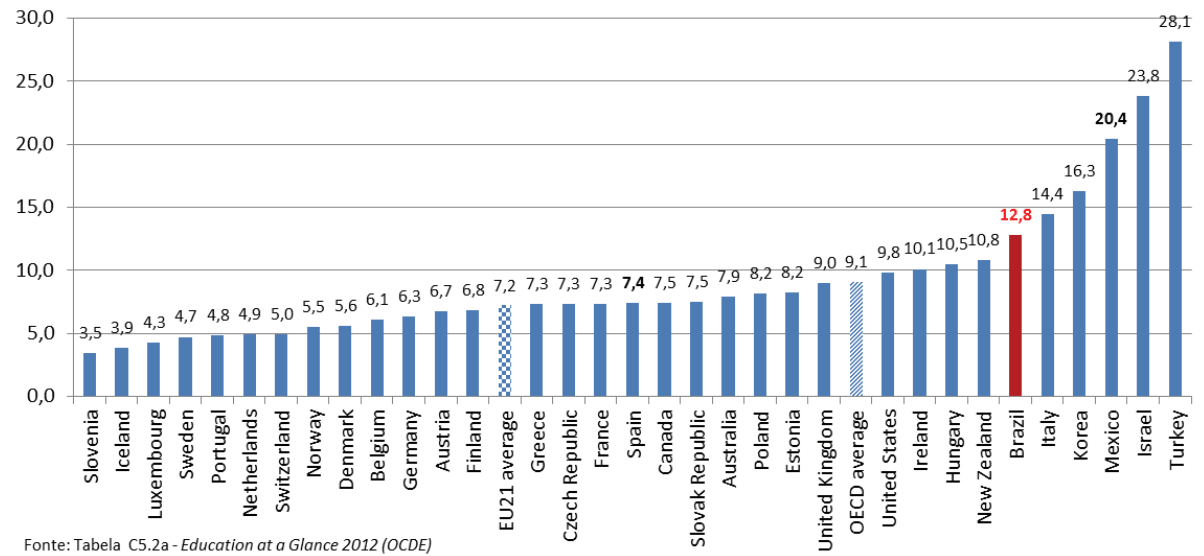

O Brasil, se considerado os NEETs apenas inativos, passa a ter uma taxa de $12,8 \%$, estando em situação pior que a da Espanha $(7,4 \%)$, mas significativamente melhor que a do México (20,4\%) (Figura 2). No contexto da América Latina, dados da CEPAL indicam que o Brasil apresenta percentuais de NEETs na faixa de 15 a 19 anos abaixo dos demais países analisados - com exceção da Bolívia estando, portanto, abaixo da média da região (Figura 3).
Pode-se concluir que o fenômeno dos jovens que nem estudam nem trabalham é mundial e que o Brasil apresenta posição relativamente vantajosa quando comparada no contexto latino-americano. Observa-se também que a taxa de NEETs por inatividade no Brasil é maior que a causada pelo desemprego jovem (12,8\% vs. $6,8 \%$ ). Neste estudo, exploro a taxa de NEET devido à inatividade, já que o desemprego jovem tende a ser transitório, como mostramos a seguir. Examinarei na seção seguinte como essa taxa evoluiu no tempo e qual era o perfil do jovem nessa situação em 2012. 
FIGURA 3: TAXA DE NEETS POR GRUPOS DE IDADE - AMÉRICA LATINA (18 PAÍSES) - 2009

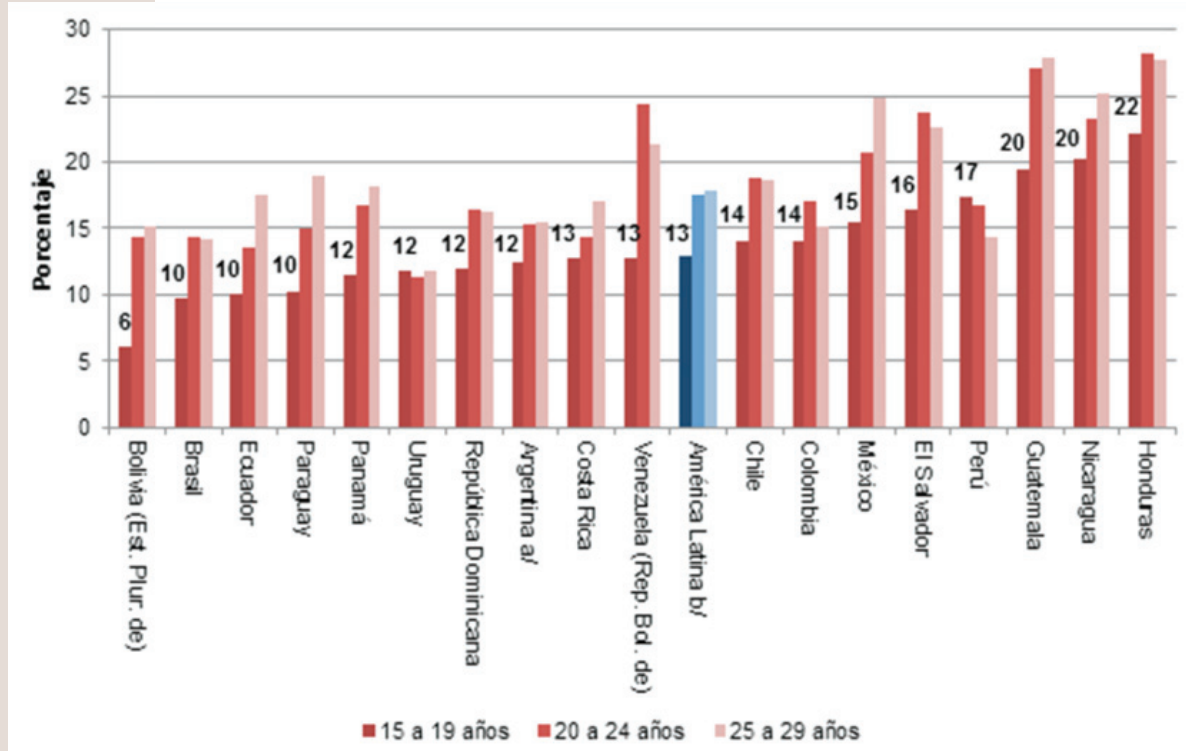

Fonte: Hopenhayn, M. (2112) El encadenamiento educación y empleo: entre eslabón perdido y reproducción de las desigualdades. Tendências em Foco n² 22, IIPE-Unesco - Sede Regional de Buenos Aires.

\section{Diagnóstico dos NEET no Brasil}

Nesta seção, analiso a evolução dos NEETs na última década e a distribuição dos jovens de 16 a 24 anos de idade quanto à situação de estudantes e trabalhadores segundo dados da PNAD 2012, explorando também a composição e o perfil desse grupo no Brasil.

\subsection{TENDÊNCIAS NO PERÍODO 2001- 2012}

Como evoluiu o número e proporção de NEETs no Brasil nos últimos anos? Os dados da PNAD no período 2001-2012 mostram que há uma relativa estabilidade no número e na taxa de jovens que não estudam, não trabalham e também não procuram trabalho na faixa etária de 16 a 24 anos (Figura 4). Nos últimos doze anos, a taxa média de NEETs no Brasil ficou em 13,6\%, com um número absoluto médio de 4,1 milhões de jovens nessa condição, havendo uma tendência de crescimento entre 2009 e $2012,{ }^{10}$ quando a taxa chega a $15 \%$ e o contingente de jovens a 4,4 milhões, maior número absoluto observado no período. A estabilidade da taxa no período é mais acentuada se somamos o percentual dos jovens que não estudam e buscam trabalho (desempregados), como faz a OCDE, alcançando uma média de 20,2\% no período. 
FIGURA 4: NÚMERO E PERCENTUAL DE JOVENS DE 16 A 24 NA SITUAÇÃO DE NEET BRASIL (2001-2012)

\section{Número e Percentual de Jovens de 16 a 24 anos na situação de NEET - Brasil (2001-2012)}

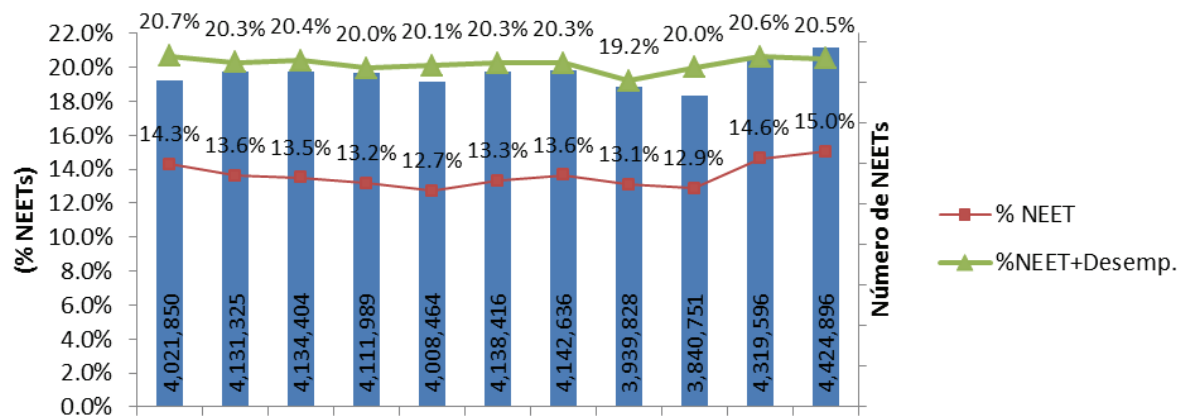

20012002200320042005200620072008200920112012

É interessante ainda observar a série histórica, por grupos de idade, nas demais categorias de situação de participação na escola e no trabalho ${ }^{11}$. Nota-se que, ao longo da década, a proporção dos jovens que só estudam cresceu em média de forma significativa para os grupos de 14-15 e 16-17 anos (Figura 5). Nesses grupos, diminuiu a proporção de quem concilia estudo e trabatho, sugerindo que houve uma redução da participação do jovem no mercado de trabalho, em benefício da escola. Essa tendência é mais forte a partir de 2007. Nos grupos de idade acima de 18 anos, a proporção dos que só estudam cai de forma significativa, crescendo em contrapartida a dos que só trabalham. Isso mostra que a idade de 18 anos é uma idade de transição importante entre a escola e o trabalho para boa parte dos jovens no Brasil. Finalmente, os NEETs parecem compor uma categoria estável ao longo do tempo quando analisada também por grupos de idade, embora cresça para os grupos de idade mais elevados.

10 Cabe ressaltar aqui que a mudança no modelo amostral da PNAD em 2011 (que melhora a representatividade da população dos municípios menores) poderia explicar, pelo menos em parte, a alta observada na taxa entre 2009 e 2011. A nova ponderação da PNAD na década de 2000-2010 ainda não estava disponível por ocasião da conclusão deste artigo.

11 Excluídas aqui as categorias "estuda e busca trabalho" e "só busca trabalho" que caracterizam os desempregados.

Revista Brasileira de Monitoramento e Avaliação | Número 6 | Julho-Dezembro de 2013

Os Jovens que não estudam nem trabalham no Brasil: uma análise do perfil, determinantes da condição e efeitos do Programa Bolsa Familia 
- FIGURA 5: PROPORÇÃO DE JOVENS SEGUNDO A PARTICIPAÇÃO NA ESCOLA E NO MERCADO DE TRABALHO POR GRUPOS DE IDADE - BEASIL 2001-2012

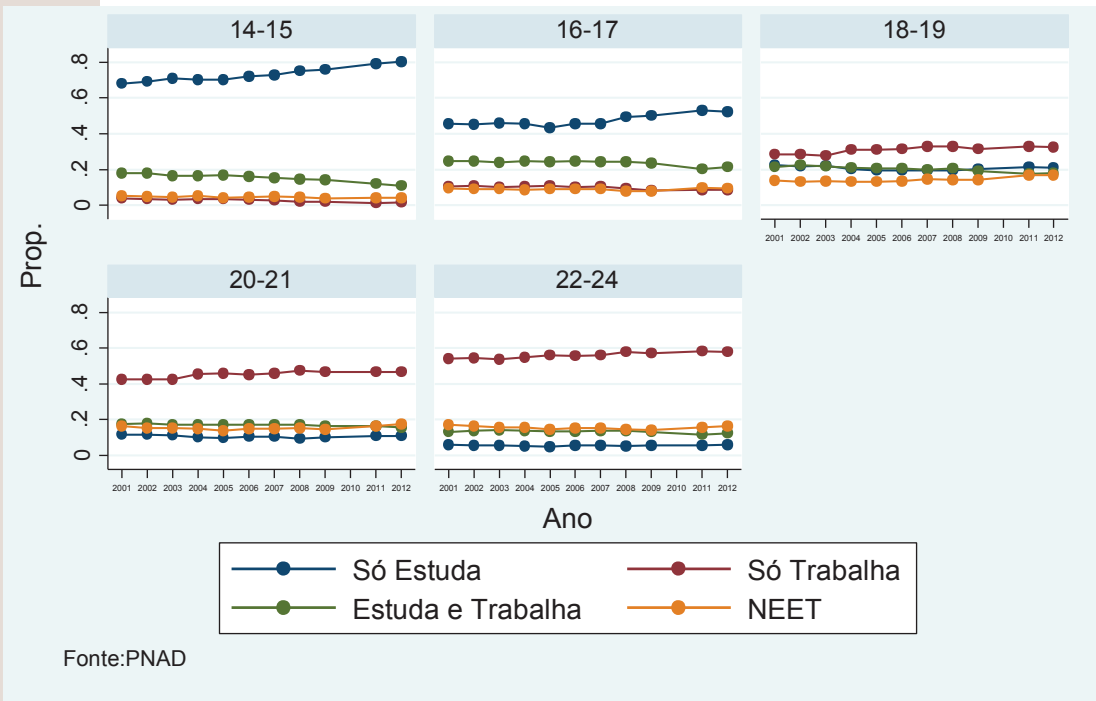

No segmento de jovens pertencentes às famílias do primeiro quintil de renda (20\% mais pobres), os grupos de idade de 14-15 e 16-17 vão observar uma tendência de crescimento bastante acentuada para a proporção dos que só estudam, saltando de um patamar de cerca de $60 \%$ para $80 \%$ no primeiro grupo, e de $40 \%$ para $60 \%$ no segundo grupo, entre 2006 e 2012 (Figura 6). A condicionalidade de educação do programa Bolsa Família (estendida até os jovens de 17 anos em 2007) poderia, em parte, explicar essa acentuada mudança na curva. ${ }^{12}$ Já para as faixas etárias mais altas, em que o programa não alcança o jovem, as curvas dos que só estudam não sofrem alteração de patamar, sendo cada vez mais baixas na medida em que se eleva a idade. Observa-se também a redução das taxas dos que só trabalham e dos que estu- dam e trabalham nos grupos 14-15 e 16-17, mostrando haver aí uma migração de jovens dessas condições para a de apenas estudantes. Por sua vez, a taxa de jovens pobres na condição de NEET cresce com a idade, não parecendo sofrer variação significativa ao longo do tempo. Contudo, ao analisarmos em separado a evolução temporal da taxa de NEETs entre os $20 \%$ mais pobres por faixas de idade (Figura 7), observamos que entre 2006 e 2009 houve uma ligeira tendência de queda nos grupos 14-15 e 16-17, enquanto os demais apresentaram uma pequena tendência de alta no mesmo período. Isso sugere que as políticas de incentivo à permanência na escola (como o Bolsa Família) podem ter contribuído para que os jovens naquelas faixas etárias tivessem menor probabilidade de se acharem inativos e fora da escola. 
FIGURA 6: PROPORÇÃO POR CONDIÇÃO DE PARTICIPAÇÃO NA ESCOLA E NO MERCADO DE TRABALHO POR GRUPOS DE IDADE (20\% MAIS POBRES) BRASIL 2001-2012

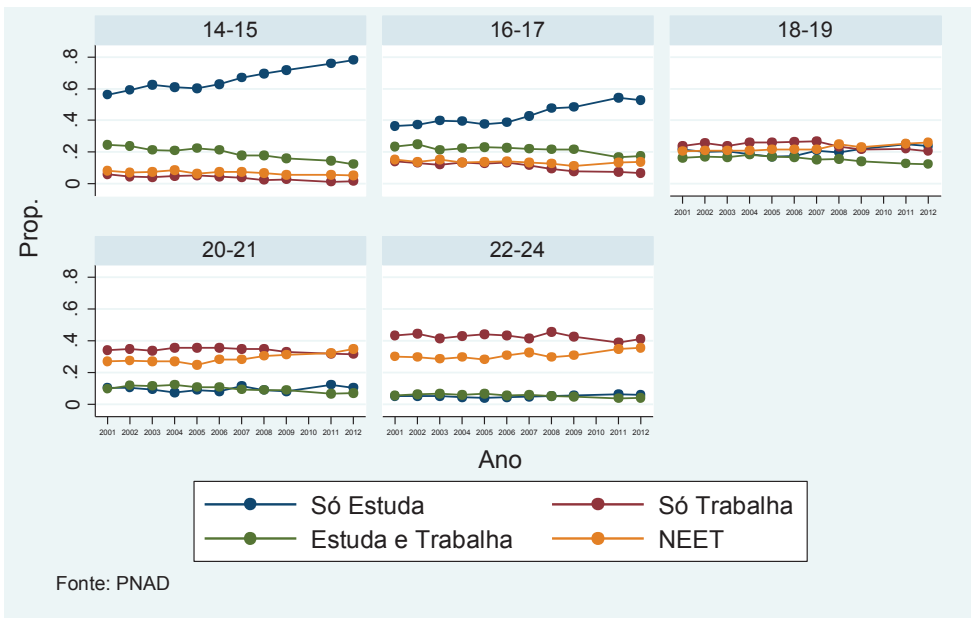

FIGURA 7: PROPORÇÃO DE JOVENS NEETS POR GRUPOS DE IDADE (20\% MAIS POBRES) 2001-2012-BRASIL

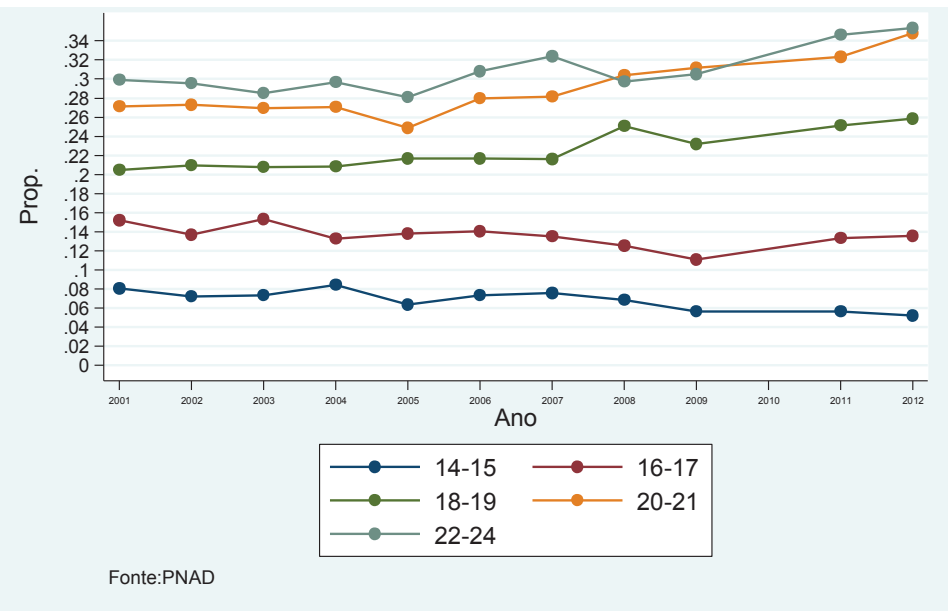

12 Além da extensão da idade de inclusão dos jovens na condicionalidade do programa, em 2007 a cobertura teria atingindo a estimativa inicial de cobertura do programa (11,2 milhões de famílias).

Revista Brasileira de Monitoramento e Avaliação | Número 6 | Julho-Dezembro de 2013

Os Jovens que não estudam nem trabalham no Brasil: uma análise do perfil, determinantes da condição e efeitos do Programa Bolsa Familia 


\subsection{PERFIL DOS JOVENS NEETS NO BRASIL - 2012}

Os dados da PNAD 2012 revelam que aos 16 anos, embora a maioria dos jovens apenas estude (60\%), já há jovens que conciliam estudo e trabalho (20\%), bem como uma pequena proporção que já está fora da escola trabalhando (5\%), buscando trabalho $(1 \%)$ ou inativo (8\%) (Figura 8). Esse último dado é preocupante, uma vez que toda criança entre 4 e 17 anos deve estar na escola básica (Emenda Constitucional no 59). ${ }^{13}$ Na medida em que a idade avança, observa-se uma relevante transição entre quem "só estuda" e "só trabalha", enquanto a proporção daqueles que conciliam estudo e trabalho tende a ser mais homogênea com tendência de queda a partir dos 18 anos. A proporção de NEETs tende a crescer entre 16 e 18 anos, permanecendo estável a partir daí até os 24 anos. 0

- Figura 8: RAZÃo da população DE 16 A 24 ANOS POR CONDIÇÃO DE ATIVIDADE/OCUPAÇÃO - BRASIL 2012

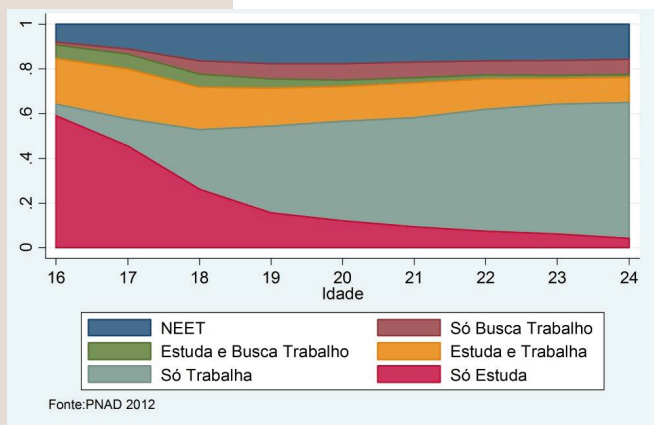

mesmo ocorre para a parcela dos jovens desempregados que não estudam (só buscam trabalho).

Seria de se esperar que a proporção de NEETs, após os 19 anos, tendesse a cair à medida que tivesse lugar a transição para o mundo do trabalho daqueles que deixaram a escola. Ocorre que, de fato, a taxa de NEET não recua para idades maiores. Mantém-se praticamente constante ao longo da idade adulta, e a inatividade explode após os 50 anos, quando a saída do mercado de trabatho daqueles que se aposentam começa a se manifestar (Figura 9) ${ }^{14}$. O que tende a diminuir é a taxa de desemprego entre os que não mais estudam; tendência claramente observada a partir dos 25 anos. O que explicaria a constância da taxa NEET após os 20 anos não somente entre os jovens, mas mesmo na idade adulta?

\section{- FIGURA 9: PROPORÇÃO NEET POR IDADE (10-70 ANOS) - BRASIL 2012}

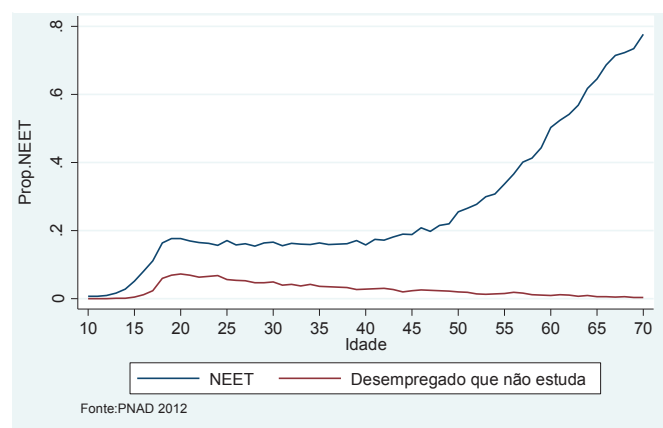


Parte da explicação pode ser encontrada na composição dos NEETs no Brasil. Tanto proporcionalmente quanto numericamente as mulheres predominam entre os NEETs, conforme mostram as Figuras 10 e 11. As mulheres observam um rápido crescimento em sua taxa entre 15 e 20 anos de idade, período em que se abre fortemente a diferença na taxa entre homens e mulheres, elas atingindo $25 \%$ aos 20 anos de idade e eles, 11\%. A partir dos 21 anos, a taxa recua para os homens até atingir 5\% aos 31 anos, mas permanece alta para as mulheres, tendendo a crescer de novo a partir dos 40 anos.

\section{- FIGURA 10: PROPORÇÃO NEET POR IDADE (10-50 ANOS) SEGUNDO SEXO - BRASIL 2012}

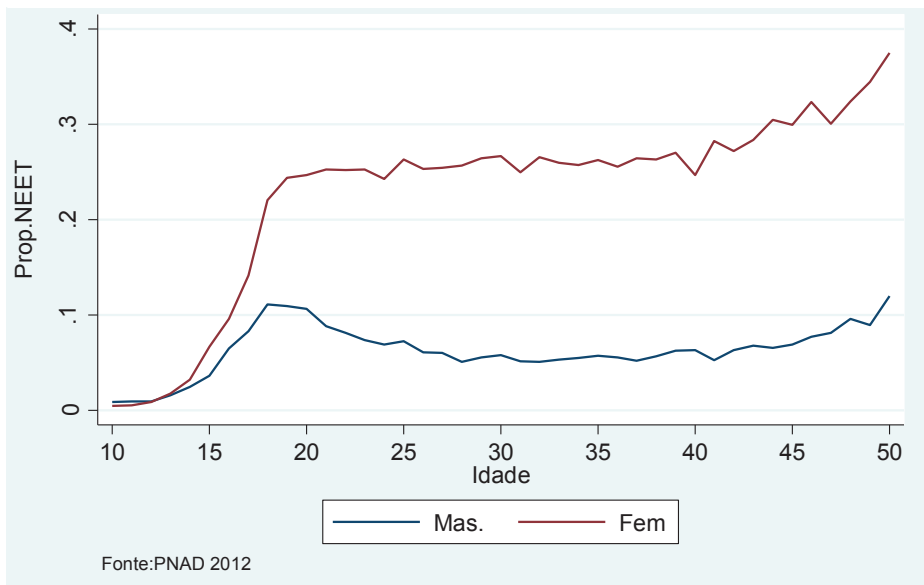

13 É verdade que a determinação constitucional estará em pleno vigor somente a partir de 2016, prazo dado aos sistemas de ensino para que se ajustem à nova legislação.

14 Aqui extrapolo o conceito de NEET, pois já não se trata mais apenas de jovens, mas também de adultos que estariam na mesma condição quanto à participação na educação e no mercado de trabalho, ou seja, são "inativos".

Revista Brasileira de Monitoramento e Avaliação | Número 6 | Julho-Dezembro de 2013 
- FIGURA 11: NÚMERO DE NEETS POR IDADE (10-50 ANOS) SEGUNDO SEXO

- BRASIL 2012

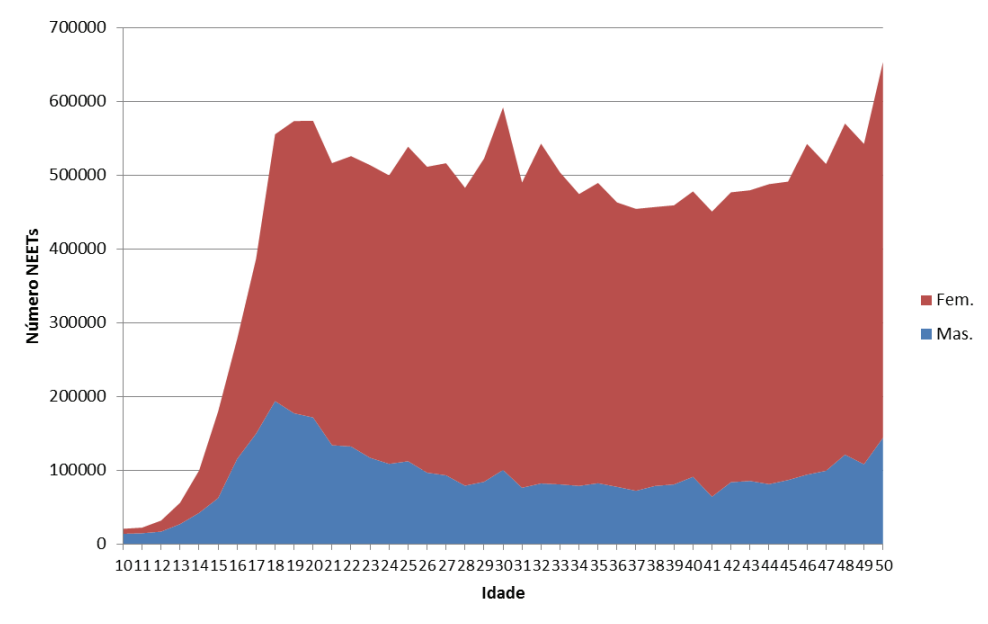

O fenômeno dos jovens que não trabalham nem estudam e não procuram emprego no Brasil é tipicamente feminino. A estabilidade da taxa nacional ao longo da idade adulta se explica pela maior prevalência de mulheres na taxa de NEETs. Mais adiante, serão discutidos os fatores que ajudam a compreender sua constância ao longo no tempo e as implicações para as políticas sociais.

Em 2012, cerca da metade dos jovens NEETs entre 16 e 24 anos não havia completado o Ensino Fundamental e cerca de 3/4 não lograram concluir o Ensino Médio. Esses jovens abandonaram a escola precocemente sem atingir o nível de escolaridade necessário para que a entrada no mercado de trabalho fosse facilitada. A distribuição dos NEETs por escolaridade para os anos de 2007 e 2012 mostra, contudo, que há uma tendência de redução da proporção daqueles que não concluíram o Ensino Fundamental e um aumento da proporção daqueles nos demais níveis de escolaridade, principalmente com Ensino Médio completo, saindo de 15\% para 23\% (Figura 12). Ao longo dos últimos anos, os jovens na condição de NEET passaram a ter um nível de escolaridade mais elevado sem que isso tenha resultado em alterações significativas na taxa nacional. Ao contrário, houve um ligeiro aumento da proporção de jovens NEETs entre 2007 e 2012 (Figura 4). 


\section{- FIGURA 12: DISTRIBUIÇÃO DE JOVENS DE 16 A 24 ANOS (20\% MAIS POBRES) SEGUNDO O NÍVEL DE ESCOLARIDADE ALCANÇADO}
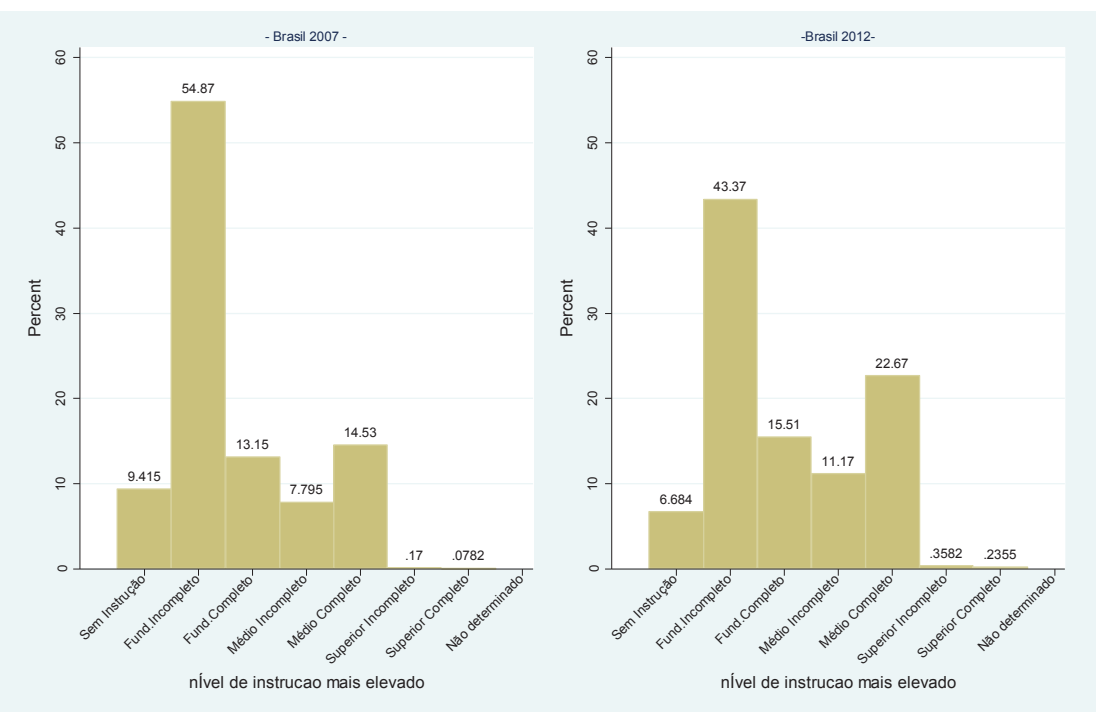

Seria de se esperar que a maior escolaridade média do jovem fosse acompanhada de maior chance de ingresso no mercado de trabalho, quando a escola já não fosse mais uma opção. Contudo o aumento na escolaridade observada não foi acompanhado de uma menor taxa NEET entre 2007 e 2012. Isso sugere que outros fatores, que não a escolarização, estariam tendo um peso maior sobre a decisão de permanecer fora da escola e inativo.

Vimos anteriormente que a maior parte dos NEETs no Brasil são mulheres. Elas representam 70\% dos NEETs na população de 16 a 24 anos, contra 30\% de homens. Observamos na Figura 13 que, dessas jovens, cerca de metade encontra-se na condição de mãe (essa proporção é uniforme por região do país). Ou seja, cerca de pouco mais de um terço do total de NEETs é de jovens mães que possivelmente estão nessa condição por se ocuparem com afazeres domésticos boa parte do tempo, cuidando do(s) filho(s) e das condições do lar. De fato, 88\% das jovens NEETs, independente da condição de mãe, declaram se ocupar de afazeres domésticos, contra apenas 30\% dos jovens. Dentre as jovens mães, 95\% declaram se ocupar com afazeres domésticos, sendo que $79 \%$ destas ocupam mais de 20 horas semanais nas tarefas do lar. Conclui-se que a maternidade pode ser um fator explicativo da grande prevalência de NEETs entre as jovens, bem como a ocupação com afazeres do lar, que pode estar relacionada com a formação de novos núcleos familiares ou, ainda, com a tutela de irmãos menores.

Revista Brasileira de Monitoramento e Avaliação | Número 6 | Julho-Dezembro de 2013 


\section{- FIGURA 13: DISTRIBUIÇÃO DOS NEETS (16-24 ANOS) POR SEXO, MATERNIDADE E OCUPAÇÃO NO LAR}

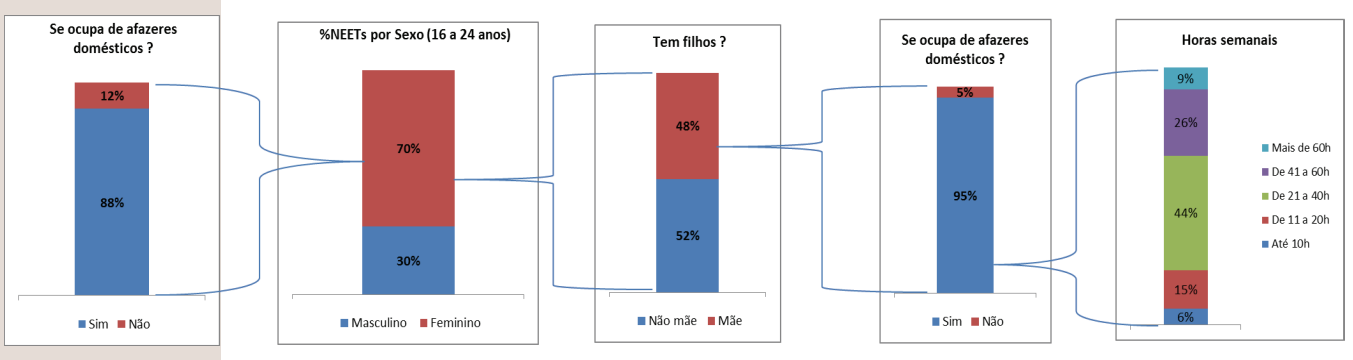

Estimado usando a PNAD 2011

A prevalência de mulheres entre os NEETs é cerca de duas vezes e meia maior que entre os homens. É uma tendência mundial, visto que são as mulheres que mais frequentemente tendem a se retirar da escola ou do mercado de trabalho em razão de matrimônio ou de gravidez. Contudo, a maternidade parece afetar as chances de uma jovem estar no grupo dos NEETs conforme o nível de renda da família (Figura 14). Se for mãe e estiver no quintil superior da renda, a chance de estar fora da escola e do trabalho é de $20 \%$, enquanto, se estiver no quintil mais pobre, a chance é de $56 \%$.

Do total das jovens NEETs, $24 \%$ são mães vivendo no $1^{\circ}$ quintil de renda enquanto apenas $1 \%$ é de mães vivendo no $5^{\circ}$ quintil de renda (Tabela 1). Isso sugere que a experiência da maternidade, entre as jovens pobres, afeta suas vidas de modo distinto de como afeta a vida das jovens não pobres. Essa diferença pode significar que enquanto as jovens do quinto quintil encontram suporte para desenvolver sua maternidade, por meio do acesso a creches e contando com apoio financeiro da família, as jovens pobres não acham suporte que as permita nem trabalhar nem continuar os estudos.
Cuidar do(s) filho(s), trabalhar em casa e depender do cônjuge e/ou de familiares passam a ser sua alternativa. $\mathrm{O}$ apoio público por meio de creches às famílias do quintil mais pobre da população poderia criar condições para que as jovens mães aproveitassem oportunidades de geração de renda e/ou de retorno à escola enquanto exercessem sua maternidade.

Quando desagregamos por cor vemos que $28 \%$ das jovens NEETs encontra-se entre as mulheres pobres e negras (Tabela 1), e que a maternidade é um fator que, associado com a pobreza, aumenta a probabilidade de a jovem estar fora da escola e do mercado de trabalho, mais ainda se for negra. Há aqui uma hipótese explicativa, ou seja, a maternidade provocaria a saída da escola e dificultaria o ingresso ou permanência no mercado de trabalho. Por outro lado, como a taxa de desemprego para as mulheres negras tende a ser relativamente maior do que para as mulheres não negras e os homens em geral, a causalidade poderia ser reversa, ou seja, a alternativa de realização social pelo casamento e/ou maternidade pode tornar-se a opção para esse segmento da população em face das dificuldades de 
- Figura 14: PREVAlÊnCIA de neEtS nO GRUPO dE MÃES (14-24 ANOS) 1o E 5o OUINTIS DE RENDA FAMILIAR PER CAPITA - BRASIL 2012

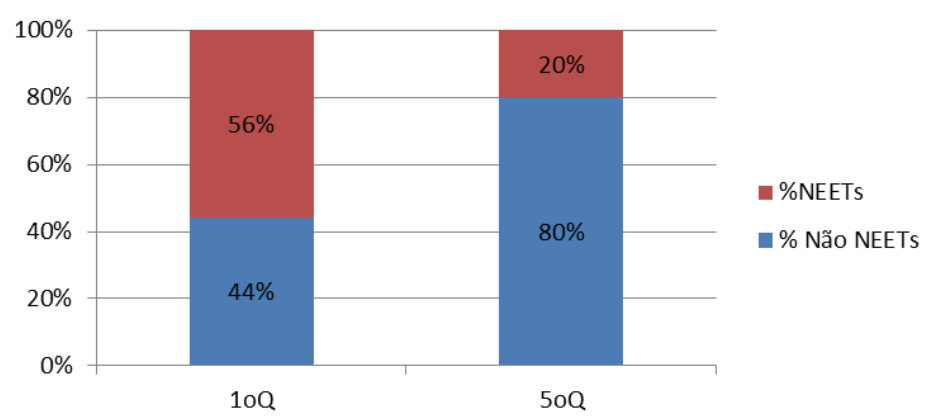

ocupação no mercado de trabalho. Nesse caso, a discriminação no mercado de trabalho contra a mulher, jovem e negra poderia estar contribuindo para que a opção da maternidade ocorresse antes dos 25 anos e acabasse por determinar uma situação de dependência e inatividade. Além disso, como já mencionado, a maior prevalência de NEETs associada à pobreza e maternidade sugere também a falta de suporte à mãe pobre para que possa conciliar trabalho e/ou estudo com a maternidade. Políticas de creche juntamente com mecanismos que garantam um piso mínimo de segurança econômica às famílias pobres poderiam contribuir para reverter o fenômeno dos NEETs dentre as mulheres das famílias pobres.

O fenômeno dos NEETs no Brasil apresenta um claro recorte de gênero (70\% são mulheres) e de nível de renda (70\% das jovens NEETs estão nos dois primeiros quintis de renda familiar per capita), mas está associado também a fatores como idade, nível educacional, maternidade e casamento no caso da mulher. A estabilidade do indicador ao longo dos últimos dez anos sugere que as políticas sociais em curso parecem não afetar de modo muito significativo esse grupo, mesmo no caso dos grupos etários beneficiados pelas políticas de transferência de renda condicionada (o que examino na seção seguinte). Embora o perfil educacional desse grupo tenha avançado nos últimos anos, isso tampouco parece ter evitado a inatividade. A maior escolaridade média dos jovens não estaria reduzindo a taxa média de NEETs entre os jovens ao longo dos últimos anos, como seria de se esperar. Na próxima seção, a participação no programa Bolsa Família é cotejada com a prevalência de NEETs entre os jovens de 15 a 24 anos, e na seção 5 examino como outra política, a oferta de creche e pré-escola, pode contribuir de forma mais efetiva para a redução do fenômeno de NEETs entre as mulheres. 
- TABELA 1: DISTRIBUIÇÃO DAS JOVENS NEETS (14 A 24 ANOS) SEGUNDO MATERNIDADE E COR POR OUINTIL DE RENDA - 2012

\begin{tabular}{|c|c|c|c|c|c|c|c|c|c|c|c|c|c|c|}
\hline & & & IÃO MÃES & & & & & & MÃES & & & & TOTAL DAS J & JENS NEET \\
\hline Quintil & Não Negra & $\%$ & Negra & $\%$ & Total & $\%$ & Não Negra & $\%$ & Negra & $\%$ & Total & $\%$ & Big Total & $\%$ \\
\hline 1 & 114,302 & $3.6 \%$ & 318,395 & $10.0 \%$ & 432,697 & $13.6 \%$ & 177,389 & $5.6 \%$ & 582,826 & $18.3 \%$ & 760,215 & $23.9 \%$ & $1,192,912$ & $37.4 \%$ \\
\hline 2 & 189,605 & $5.9 \%$ & 292,065 & $9.2 \%$ & 481,670 & $15.1 \%$ & 183,195 & $5.7 \%$ & 347,772 & $10.9 \%$ & 530,967 & $16.7 \%$ & {$[1,012,637$} & $31.8 \%$ \\
\hline 3 & 138,558 & $4.3 \%$ & 164,606 & $5.2 \%$ & 303,164 & $9.5 \%$ & 89,189 & $2.8 \%$ & 101,347 & $3.2 \%$ & 190,536 & $6.0 \%$ & 493,700 & $15.5 \%$ \\
\hline 4 & 118,551 & $3.7 \%$ & 104,896 & $3.3 \%$ & 223,447 & $7.0 \%$ & 47,411 & $1.5 \%$ & 49,727 & $1.6 \%$ & 97,138 & $3.0 \%$ & 320,585 & $10.1 \%$ \\
\hline 5 & 86,931 & $2.7 \%$ & 45,044 & $1.4 \%$ & 131,975 & $4.1 \%$ & 22,556 & $0.7 \%$ & 13,084 & $0.4 \%$ & 35,640 & $1.1 \%$ & 167,615 & $5.3 \%$ \\
\hline Total & 647,947 & $20.3 \%$ & 925,006 & $29.0 \%$ & 1572953 & $49.3 \%$ & 519,740 & $16.3 \%$ & 1094756 & $34.3 \%$ & 1614496 & $50.7 \%$ & $3,187,449$ & $100.0 \%$ \\
\hline
\end{tabular}

\section{Os jovens por condição de atividade e o Programa Bolsa Família (BF)}

Tomando-se todo o grupo de jovens de 15 a 24 anos de idade entre os $20 \%$ mais pobres, as diferenças entre beneficiários e não beneficiários do BF são estatisticamente significativas para todas as categorias de análise, exceto para os que "só estudam" e "estudam e buscam trabalho" (Figura 15). ${ }^{15}$ Os beneficiários estão em maior proporção entre os que "só trabalham" e "estudam e trabalham". Já os não beneficiários são encontrados em maior proporção entre os que "só buscam trabalho" (desempregados) e "nem estudam nem trabalham" (NEETs). Ou seja, os não beneficiários são prevalentes entre os inativos e desempregados que não estudam.

Comparando-se agora os jovens de 14 a 24 anos na condição de NEET em 2012 (Figura 16), observa-se que, entre os 20\% mais pobres, aqueles jovens pertencentes a famílias beneficiárias do BF tem menor probabilidade de estar na condição de NEET. As diferenças são significativas entre 14 e 20 anos de idade ${ }^{16}$. A partir dos 21 anos, as diferenças na probabilidade NEET entre beneficiários e não beneficiários não são distinguíveis estatisticamente.

A análise por gênero (Figura 17) permite verificar a diferença no padrão de dispersão da taxa NEET entre homens e mulheres ao longo das várias idades. É visível como o fenômeno atinge mais as mulheres. A partir dos 17 anos, a probabilidade das mulheres se encontrarem na condição de NEET aumenta significativamente em relação à dos homens. Contudo, até os 20 anos, as mulheres de famílias estimadas como participantes do BF apresentam uma taxa estatisticamente menor que as não beneficiárias ${ }^{17}$. A partir dos 21 anos, as diferenças não são mais significativas. 
FIGURA 15: PROPORÇÃO DE JOVENS 15-24POR SITUAÇÃO DE ESCOLA E TRABALHO 20\% MAIS POBRES SEGUNDO A CONDIÇÃO DE BENEFICIÁRIO NO BF - BRASIL 2012

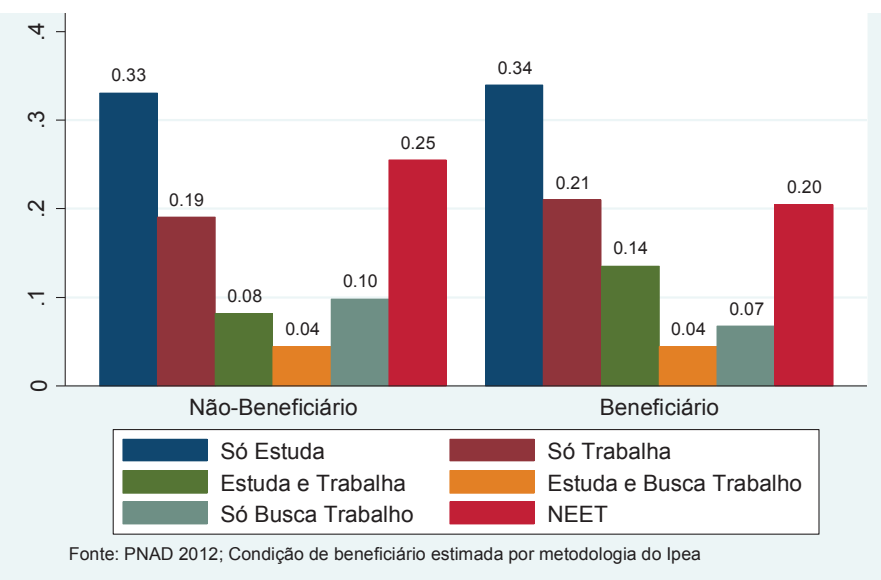

- Figura 16: PROPORÇÃo dE NEETS POR IDADE EM FAMILIAS DOS 20\% MAIS POBRES SEGUNDO A PARTICIPAÇÃO NO BF - BRASIL 2012

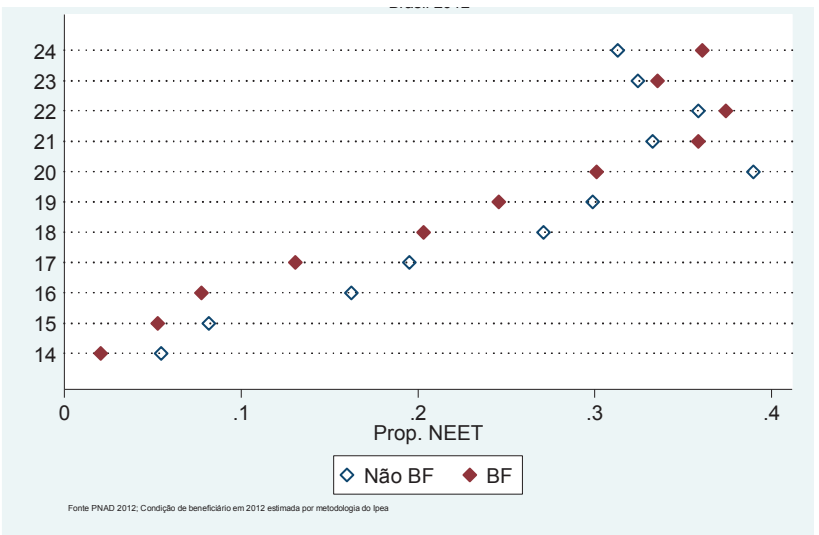

15 A condição de beneficiário do Bolsa Família é estimada seguindo a metodologia desenvolvida pelo IPEA para aplicação sobre os dados da PNAD (Texto para Discussão No 1654/lpea).

16 Para a idade de 19 anos, a significância é 10\%.

17 Com exceção do grupo de 19 anos.

Revista Brasileira de Monitoramento e Avaliação | Número 6 | Julho-Dezembro de 2013

Os Jovens que não estudam nem trabalham no Brasil: uma análise do perfil, determinantes da condição e efeitos do Programa Bolsa Familia 
- FIGURA 17: PROPORÇÃO DE NEETS POR IDADE EM FAMILIAS DOS 10 QUINTIL DE RENDA BF X NÃO BF - BRASIL 2012

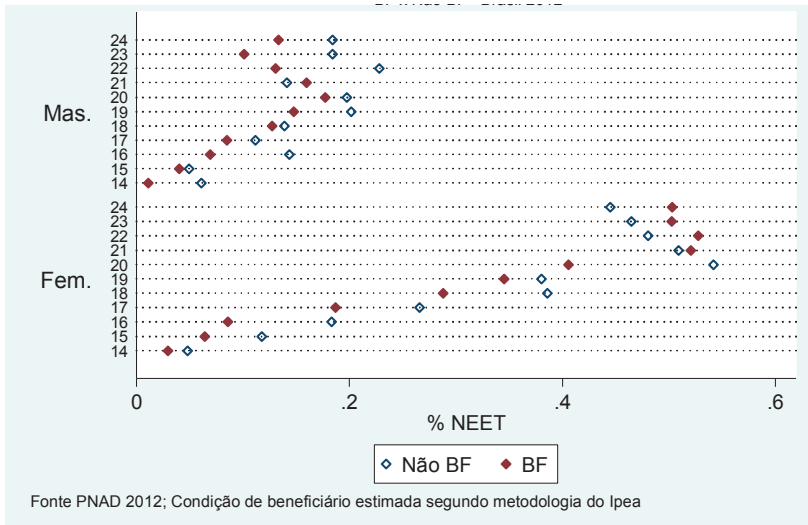

Embora essas comparações não permitam inferir que as diferenças observadas nas taxas de NEET sejam efeito direto do BF, por outro lado não se pode afirmar que entre os beneficiários haja maior grau de inatividade, pois o contrário disso é o que dizem os dados.

Considerando que no Brasil o fenômeno dos NEETs ocorre, sobretudo, entre as mulheres (elas representam $70 \%$ dos NEETs), sendo metade delas mães que ocupam grande parte de seu tempo com afazeres domésticos, cabe investigar o grau de associação do fenômeno entre as mulheres com outros fatores como a escolaridade, o casamento, a maternidade e sua participação no programa Bolsa Família.

\section{Usando um modelo probabilístico para estimar os fatores intervenientes na propensão das jovens estarem na condição de NEET}

A condição de NEET como função de variáveis de interesse (por exemplo, ser beneficiário do BF ou ser casada) pode ser estimada por meio de um modelo econométrico do tipo probit, em que a variável NEET (variável dependente) é uma variável binária que assume os valores o ou 1 (representando respectivamente os estados "ser NEET" e "não ser NEET") e as variáveis independentes representam o conjunto 
de fatores associados à condição de NEET. O modelo probit irá relacionar a probabilidade da jovem se encontrar na condição de NEET com as variáveis de interesse, representadas pelo vetor $X i$, por meio da função de distribuição acumulada $\Phi$ (.).

$$
\operatorname{Pr}(\text { NEETi }=1 \mid X i)=\Phi\left(X i^{\prime} \beta\right)
$$

Duas subamostras com base na amostra da PNAD 2012 são analisadas: as mulheres de 14 a 24 anos e as mulheres de 14 a 24 anos que são mães. As variáveis que entram nos modelos para cada subamostra estão descritas a seguir.

\section{- 1) Mulheres de 14 a 24 anos:}

1.1) $X i=(B F$, idade, negro, renda, nível educacional, região, casada, mãe).

1.2) $X i=(B F$, idade, negro, renda, nível educacional, região, casada, filhos 0-3, filhos 4-6, filhos 7-14).

\section{- 2) Mães de 14 a 24 anos:}

2.1) $X i=(B F$, idade, negro, renda, nível educacional, região, casada, acesso à creche, acesso à pré-escola).

\subsection{SUBPOPULAÇÃO DE MULHERES DE 14 A 24 ANOS: OS FATORES OUE INFLUENCIAM A PROBABILIDADE NEET}

No primeiro modelo estimado, além do efeito $\mathrm{BF}^{18}$ procuramos avaliar também o efeito que o casamento (entendido aqui como coabitação) e a maternidade teriam sobre a probabilidade de a jovem estar na condição de NEET. No segundo modelo, a maternidade é desmembrada por faixa etária dos filhos (0-3, 4-6 e 7-14 anos), de modo a permitir identificar diferentes efeitos da maternidade na probabilidade da jovem ser NEET segundo a idade dos filhos ${ }^{19}$.

Nota-se uma associação da participação no Bolsa Família com uma redução da probabilidade da jovem ser NEET de 3,3 p.p. (Figura 18). A relevância da renda familiar para o agravamento do fenômeno entre as mulheres também é grande, tendo as jovens do primeiro quintil de renda uma probabilidade 19,5 p.p. maior de estarem fora da escola e do mercado de trabalho do que as jovens do $5^{\circ}$ quintil de renda. $\mathrm{O}$ casamento tem efeito médio também significativo, aumentando em 14,7 p.p. a probabilidade da jovem NEET. Esse efeito é independente do efeito da jovem ser mãe, que aumenta em 9,0 p.p. a probabilida-

\footnotetext{
18 O uso do termo "efeito" associado ao programa não pode ser interpretado como efeito causal, ou seja, não é uma estimativa não enviesada do impacto do programa sobre a probabilidade NEET. Trata-se da associação da participação no BF com a probabilidade NEET ajustada para as demais características das pessoas que integram o modelo. O mesmo se aplica ao uso do termo para as demais variáveis do modelo.
}

19 Foram testadas e consideradas para os dois modelos todas as interações da variável BF com os demais fatores.

Revista Brasileira de Monitoramento e Avaliação | Número 6 | Julho-Dezembro de 2013 
de NEET. Esses efeitos são não só independentes entre si, mas também em relação aos demais fatores que integram o modelo. A região geográfica e a categoria cor/raça não parecem influir na chance da jovem ser NEET quando considerados em conjunto com os demais fatores, enquanto o nível educacional reduz e a idade aumenta essa chance (não representados no gráfico). As mulheres têm uma probabilidade 10 p.p. maior do que o homem de estar na condição de NEET, status fortemente influenciado pelo fator renda e pelo fato de estar casada ou de ser mãe.

Substituindo-se a variável "mãe" no modelo por três variáveis que identificam se a jovem tem filhos nas faixas etárias de 0 a 3, 4 a 6 ou 7 a 14 anos, observamos que a maternidade aumenta a probabilidade da jovem estar na condição de NEET de forma significativa apenas no caso dos filhos terem entre 0 e 3 anos de idade (Figura 19). Nesse caso, as chances da jovem estar como NEET aumentam 12 p.p. em relação à jovem que não tem filhos nessa faixa etária (independente de ter filhos em outra faixa). Já ter filhos entre 4 a 6 anos

- FIGURA 18: EFEITO MARGINAL MÉDIO DOS FATORES SOBRE A PR(NEET) PARA MULHERES DE 14 A 24 ANOS BRASIL - 2012

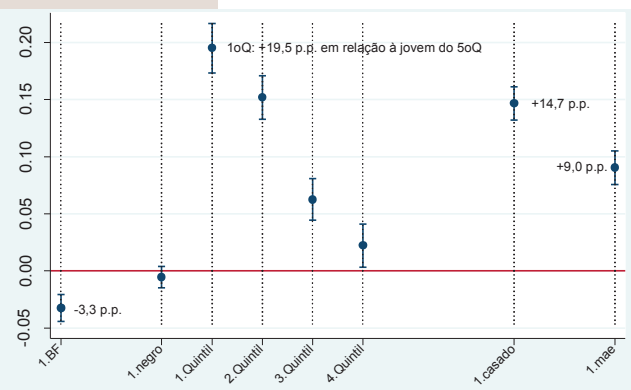

de idade está associado com uma menor probabilidade de a jovem estar simultaneamente fora do mercado de trabalho e da escola. Esses resultados sugerem que a jovem tende a estar fora da escola e do mercado de trabalho na fase inicial da maternidade, quando os filhos são menores. Isso poderia se explicar pela escolha da mãe em permanecer junto ao filho quando este é ainda muito pequeno. Por outro lado, para a faixa etária de 0 a 3 anos, a cobertura de creche no Brasil é pequena (21\%), não havendo muita alternativa para a jovem mãe nessa fase, a não ser contar com apoio de familiares em casa (mãe, sogra etc.), o que também pode explicar o efeito na probabilidade NEET devido aos filhos nessa faixa etária. Já na faixa etária de 4 a 6 anos, a cobertura escolar alcança um patamar bem mais elevado (78\%), possibilitando que a jovem ingresse no mercado de trabalho ou retorne aos bancos escolares. No caso dos filhos de 7 a 14 anos, não há diferença para a mãe na probabilidade NEET. Nesse caso, não só a cobertura escolar é muito elevada, mas também a idade da criança facilita que a mãe se ausente para trabalhar e/ou estudar.

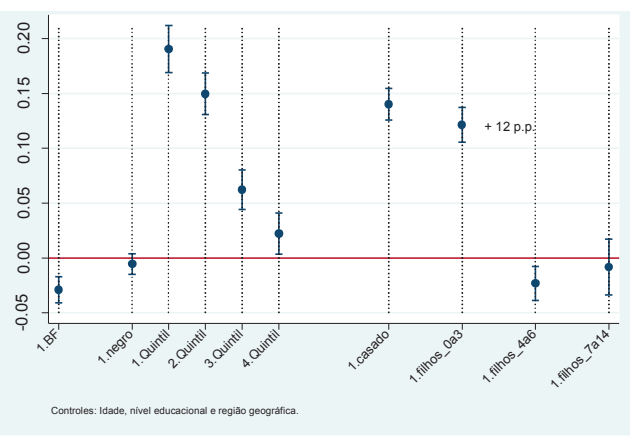


$O$ efeito de ter filhos de 0 a 3 anos de idade sobre a probabilidade NEET, segundo a estimativa do mesmo modelo, varia fortemente com a renda familiar per capita, conforme mostra a Figura 20, embora em todas as faixas de renda a fase inicial da maternidade pareça influir na probabilidade NEET.

Se esse efeito é menor para as jovens de maior renda, é possível que elas estejam tendo acesso (por meio da renda) a serviços que as jovens de famílias mais pobres não logram obter na mesma proporção. É o que mostra a Figura 21. Acesso a creche para todos os filhos de 0 a 3 anos só existe para $13 \%$ das jovens do primeiro quintil de renda. Já entre as jovens do quintil de maior renda, sobe para $28 \%$ de mães.

FIGURA 20: EFEITO MARGINAL MÉDIO DE FILHOS (O-3) SOBRE A PR (NEET) PARA AS MULHERES DE 14 A 24 ANOS SEGUNDO O OUINTIL DE RENDA FAMILIAR PER CAPITA BRASIL 2012

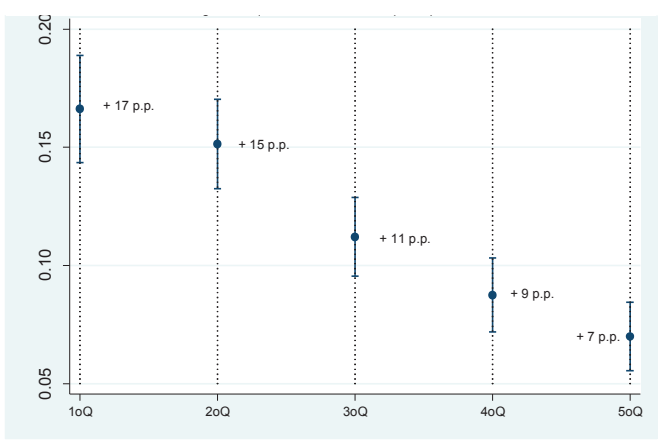

\subsection{SUBPOPULAÇÃO DE MÃES DE} 14 A 24 ANOS: OS FATORES OUE INFLUENCIAM A PROBABILIDADE NEET

Para estimar o efeito do acesso à creche ou à escola para os filhos na probabilidade NEET das mães entre 14 e 24 anos de idade, são selecionadas da PNAD apenas as mães com filhos nas faixas etárias de 0-3, 4-6 e nas duas simultaneamente. Interessa analisar os efeitos que o acesso à creche e à pré-escola ou escola teriam na probabilidade da jovem estar fora da escola e do mercado de trabalho. A Tabela 2 reporta os efeitos marginais médios das variáveis de interesse sobre a probabilidade NEET.

\section{- Figura 21: PROPORÇÃO dE JOVENS MÃES COM FILHOS DE O A 3 ANOS COM ACESSO À CRECHE PARA TODOS OS FILHOS SEGUNDO O OUINTIL DE RENDA FAMILIAR PER CAPITA - BRASIL 2012}

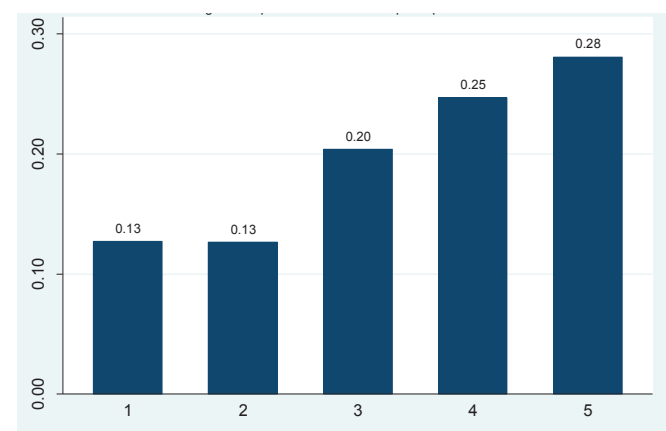


TABELA 2: PROBIT SOBRE A TAXA DE NEET

\begin{tabular}{|c|c|c|c|c|c|}
\hline \multirow[t]{2}{*}{ PNAD 2012} & & Modelo(1) & Modelo(2) & Modelo(3) & Modelo(4) \\
\hline & & Só Filhos 0 a 3 & Só Filhos 4 a 6 & Filhos 0-3 e 4-6 & Filhos 0-3 e 4-6 \\
\hline \multirow{9}{*}{$\begin{array}{l}\text { Bolsa Familia } \\
\text { Negro } \\
\text { Quintil (1) }\end{array}$} & & $\mathrm{dy} / \mathrm{dx}$ & $\mathrm{dy} / \mathrm{dx}$ & $\mathrm{dy} / \mathrm{dx}$ & $\mathrm{dy} / \mathrm{dx}$ \\
\hline & & -0.002 & -0.005 & -0.038 & -0.044 \\
\hline & & $-0.036^{*}$ & -0.020 & -0.051 & 0.049 \\
\hline & & & & & \\
\hline & 1 & $0.267 * * *$ & $0.243^{* * *}$ & $0.349 * * *$ & $0.353^{* *}$ \\
\hline & 2 & $0.219 * * *$ & $0.160^{* * *}$ & 0.166 & 0.169 \\
\hline & 3 & 0.039 & -0.049 & 0.037 & 0.035 \\
\hline & 4 & $-0,007$ & -0.047 & 0.056 & -0.055 \\
\hline & & & & & \\
\hline \multicolumn{2}{|c|}{ Casada } & $0.192^{* * *}$ & $0.158^{* * *}$ & $0.180^{* * *}$ & $0.182^{* * *}$ \\
\hline \multicolumn{2}{|c|}{ Acesso à Creche $p /$ todos de 0 a 3} & $-0.229 * * *$ & - & -0.013 & - \\
\hline \multicolumn{2}{|c|}{ Acesso à Escola/Creche p/ todos de 4 a 6} & - & $-0.099 * * *$ & -0.061 & - \\
\hline \multicolumn{2}{|c|}{ Acesso à Escola/Creche $\mathrm{p} /$ todos de $0 \mathrm{a} 6$} & - & - & - & -0.031 \\
\hline & $\mathrm{N}$ & 3727 & 974 & 650 & 650 \\
\hline \multicolumn{6}{|c|}{ (1) Categoria de base: quinto quintil } \\
\hline \multicolumn{6}{|c|}{ (2) As mães não tem filhos de 7 a 14} \\
\hline \multicolumn{3}{|c|}{ Controles: Idade, nível educacional e região geográfica } & & & \\
\hline
\end{tabular}

(*) $<0.10 ;(*)<0.05 ;(* *)<0.01$

As estimativas do modelo (1) mostra que no grupo de mães apenas com filhos de 0 a 3 anos de idade, a mãe com acesso à creche para todos os filhos tem, em média, uma probabilidade 23 p.p. menor de estar na condição de NEET do que a mãe que não tem sua(s) criança(s) na creche. Esse efeito independe do quintil de renda, cor, idade, nível educacional, região ou se a jovem é casada ou participante do Bolsa Família. Para esse grupo, a participação no programa não afeta a probabilidade NEET. Pode-se entender que as mães muito jovens com crianças naquela faixa etária tenderiam a conciliar menos a maternidade com escola e/ou trabalho na ausência de serviços de creche, e que mesmo o acesso ao benefício do Bolsa Família não compensaria a au- sência do serviço de cuidado à criança. Viver com um cônjuge aumenta de forma independente (19 p.p.) as chances de a jovem estar fora da escola e inativa. Do mesmo modo, a faixa de renda familiar tem grande efeito se a jovem está no primeiro ou segundo quintil de renda comparado a estar no quintil mais alto.

Para o grupo de mães apenas com filhos de 4 a 6 anos de idade - modelo (2) -, substituímos a variável acesso à creche pela variável acesso à escola/creche, visto que nessa faixa etária a PNAD mostra que há crianças frequentando tanto creches quanto pré-escolas, ou mesmo já no Ensino Fundamental regular. $\mathrm{O}$ acesso à escola aparece associado com uma redução de 10 p.p. na probabilidade 
da jovem estar no grupo NEET. Também para esse grupo, a participação no BF não aparece associada a uma redução na probabilidade NEET. Ou seja, tanto para as mães com filhos de 0 a 3 quanto para as mães com filhos de 4 a 6 anos, a oferta de serviços de creche e escola é o único entre os fatores analisados, além do nível educacional da mãe, que aparece associado com uma menor probabilidade NEET.

Finalmente, tomando-se o grupo de mães com filhos nas duas faixas etárias, o efeito estimado do acesso à creche independente do acesso à escola para o(s) filho(s) de 4 a 6 é negativo, mas não significativo - modelo (3). O mesmo acontece para o caso da mãe ter acesso à escola para o(s) filho(s) de 4 a 6 anos independente de ter acesso à creche para os menores. Em princípio, não é difícil entender porque isso ocorre. Nesse grupo, as mães têm filhos nas duas faixas etárias. Embora $76 \%$ delas tenham acesso à pré-escola ou escola para os filhos de 4 a 6 anos, dessas, cerca de $70 \%$ não têm acesso à creche para os de 0 a 3 anos. Ou seja, essas mães em grande parte estão apenas parcialmente assistidas por serviços que viabilizem o retorno à escola ou ao mercado de trabalho. Portanto, o acesso à pré-escola ou escola nesse caso não contribui para reduzir a probabilidade NEET, pois as crianças menores ainda dependem integralmente dos cuidados da mãe.

Curiosamente o modelo (4), que estima o efeito do acesso à creche e escola para todos os filhos de 0 a 6 anos, não mostra nenhuma redução estatisticamente significativa na probabilidade NEET, embora o coeficiente também seja negativo como no modelo (3). Esse resultado coloca uma dificuldade para a interpretação, pois seria de se esperar que o acesso à creche e à escola para todos os filhos tivesse uma forte associação com a redução na probabilidade NEET, pois a mãe teria onde deixar todos os filhos. Podemos identificar aqui um grupo de mães que segue uma tendência dominante no Brasil até os anos 1960,20 em que se esperava da mulher que se casasse, tivesse filhos e pudesse se dedicar integralmente à família. As escolhas individuais nesse grupo podem ter um peso maior que a presença de políticas que, em tese, favoreceriam a inserção da mulher no mercado de trabalho ou seu retorno aos bancos escolares.

20 Segundo Scott (2012), os anos 1960 foram um marco na trajetória de transformações para as mulheres no Brasil. Em 1961, a Lei de Diretrizes e Bases da Educação (LDB) garantiu equivalência a todos os cursos de nível Médio permitindo que as alunas do curso normal pudessem seguir para o curso Superior. Em 1962, tem início o comércio da pílula anticoncepcional no Brasil, o que começa a dar à mulher maior liberdade e possibilidade de exercer seus direitos reprodutivos. É nesse período também que o movimento feminista começa a ganhar impulso no Brasil, não obstante o período ditatorial que se inaugura em 1964.

Revista Brasileira de Monitoramento e Avaliação | Número 6 | Julho-Dezembro de 2013 
Essa tendência pode ser agravada pelo fato de, no Brasil, existirem poucas oportunidades de empregos em horário parcial e/ou de flexibilização de horários e locais de trabalho, fazendo que a opção pelo trabalho remunerado fora de casa, mesmo com a oferta de creche e pré-escola, tenha um custo elevado para mãe, o da permanência por longas horas do dia longe dos filhos. Por outro lado, não se considera na análise o período de permanência na creche e escola das crianças. O horário parcial do atendimento escolar, conjugado com a falta de empregos em tempo parcial e com uma cultura em que ainda conta-se pouco com a participação do homem na divisão de tarefas no lar, pode explicar o "não efeito" do atendimento para todos os filhos. Deve-se considerar ainda que a presença de filhos em grupos de idades distintos, que levam a que o atendimento se dê em unidades de serviço distintas (creche para os de 0 a 3 e pré-escola ou escola para os de 4 a 6), possivelmente distantes uma da outra pode, na prática, não facilitar o dia a dia da mãe, como se imagina, não criando condições para o ingresso no mercado de trabalho.

Ainda que parciais, esses resultados sugerem como política complementar às transferências de renda a oferta de serviços de Educação Infantil, principalmente para as mães dos dois primeiros quintis de renda, nos quais se acumulam a grande parcela das jovens em condição de NEET. O efeito desses serviços em reduzir as chances de exclusão da mulher da escola e do mercado de trabalho, de um lado, contribuiria para o aumento do capital humano (no caso de permanência na escola das jovens), de outro, contribuiria para a geração de renda na família (no caso de ingresso no mercado de trabalho). Se as jovens já possuem, em média, maior escolaridade que os jovens (mesmo nos quintis de renda mais baixos), há uma perda de oportunidade de ganhos de renda na família quando ela se ausenta do mercado de trabalho por não ter com quem deixar seus filhos. $\mathrm{O}$ aumento da renda familiar via inclusão produtiva da muLher pode favorecer a redução da necessidade de transferências de renda, mas depende da oferta de serviços de atenção à criança na forma de acesso à creche e à pré-escola. Esse acesso, por sua vez, favorece o desenvolvimento infantil e a preparação para a etapa escolar, principalmente nas faixas de renda mais baixas, em que as dificuldades da família em oferecer um ambiente estimulante aos pequenos são maiores. A oferta de creches e pré-escolas associada à transferência condicionada de renda parece ser uma combinação melhor na busca da interrupção definitiva do ciclo de reprodução intergeracional da pobreza. Pode representar, ainda, uma possível porta de saída no médio prazo para muitas famílias com crianças participantes do programa Bolsa Família, na medida em que viabilizam o ingresso da mulher em atividades produtivas fora do lar.

Esping-Andersen mostra que, na experiência dos países europeus, a probabilidade de uma criança se encontrar em situação de pobreza quando a mãe está empregada cai por um fator de três a quatro, com efeitos ainda maio- 
res no caso de mães solteiras. A oferta de serviços de creche e pré-escola é o que possibilita essa inserção no mundo laboral. Por exemplo, a Dinamarca, onde o serviço de creche se universalizou a partir dos anos $1960 \mathrm{e}$ o custo da creche para as famílias de menor renda chega a zero, conta com uma participação na força de trabalho de $81 \%$ das mães solteiras, enquanto que, no Reino Unido, onde essa universalização não foi alcançada, mesmo contando com benefícios sociais atrelados à presença de crianças na família (child benefit), a taxa de pobreza infantil é a uma das maiores da Europa Ocidental e a taxa de participação das mães solteiras na força de trabalho é de apenas 35\%. ${ }^{21}$ Reconhece-se, portanto, que a participação da mulher na força de trabalho depende fundamentalmente do acesso a serviços de cuidado à infância que sejam seguros e acessíveis do ponto de vista econômico e territorial para as famílias.

\section{Conclusão}

A abordagem do fenômeno dos jovens que estão fora do mercado de trabalho e da escola requer que se conheça melhor o problema, identificando o perfil dos jovens nessa situação e suas motivações no contexto brasileiro. Devido à heterogeneidade das situações que ocorrem no Brasil e no mundo, generalizações e simplificações com base em dados escassos podem levar erroneamente a conclusões sobre suas causas e até mesmo sobre a existência do problema, que passam longe da realidade da vida dos jovens. Em consequência, os gestores podem adotar medidas desnecessárias ou insuficientes para lidar com o problema. Também é necessário investigar melhor os fatores de risco que podem induzir o jovem à inatividade de caráter indesejável. Por outro lado, deve-se entender que a inatividade temporária por opção do jovem não necessariamente implica uma situação problemática, como argumentado no início deste artigo. Busquei mostrar que, no caso brasileiro, o perfil do jovem nessa situação tem um forte viés de gênero e de renda. É um fenômeno que atinge desproporcionalmente as mulheres, e, dentre essas, as mães das camadas de renda mais baixa, bem como as mulheres casadas. Isso por si só já nos leva a concluir que medidas baseadas nas análises dos países do Norte, onde a taxa de desemprego elevada do jovem é o fator mais destacado, podem não ser as mais efetivas para o Brasil.

Buscar a qualificação profissional do jovem (em nível Médio ou Superior) antes ou concomitante ao ingresso no mercado de trabalho, facilitar a transição escola-trabalho, auxiliar o jovem na busca de emprego e vencer barreiras estruturais à demanda por jovens no mer- 
cado de trabalho são iniciativas que até podem contribuir para a redução do problema dos NEETs. Ocorre que no Brasil o peso do desemprego como fator explicativo do problema é menor, visto que a taxa de desemprego dos últimos dez anos vem em ritmo de queda e atingiu um dos patamares mais baixos da série. Desse modo, a estratégia comumente seguida nos países desenvolvidos em momentos de crise do emprego, como a extensão do tempo nos bancos escolares ("se não há emprego, continue estudando") ou o subsídio ao emprego do jovem, podem não ser as melhores estratégias para o enfrentamento do problema no contexto brasileiro. A especificidade do problema no Brasil que prevalece entre as mulheres, dentre as quais metade são mães, e muitas são pobres e negras, sugere que políticas de combate à discriminação no acesso aos postos de trabalho (racial e de gênero) e de apoio às jovens mães com creches e transferência de renda podem ser mais efetivas. A articulação das políticas de atendimento à infância e de proteção social parece ser o caminho mais promissor. 


\section{Referências bibliográficas}

CHEN, Y. W. 2011. Once a NEET always a NEET? Experiences of employment and unemployment among youth in a job training programme in Taiwan. International Journal of Social Welfare, 20, 33-42.

ESPING-ANDERSEN, Gosta 2009. The Incomplete Revolution - Adapting to Women's New Roles, Cambridge, Polity Press.

FINLAY, Ian; SHERIDAN, Marion; MCKAY, Jane \& Nudzor, Hope 2010. Young People on the Margins: In Need of More Choices and More Chances in Twenty-First Century Scotland. British Educational Research Journal, 36, 851-867.

HOPENHAYN, Martín 2012. El encadenamiento educación y empleo: entre eslabón perdido y reproducción de las desigualdades. Oct/2012 ed.: IIPE-Unesco.

MAGUIRE, Sue 2008. Paying Young People to Learn--Does It Work? Research in Post-Compulsory Education, 13, 205-215.
OECD 2012. How successful are students in moving from education to work?, OECD Publishing.

PEMBERTON, S. 2008. Tackling the NEET generation and the ability of policy to generate a 'NEET' solution - evidence from the UK. Environment and Planning C: Government and Policy, 26, 243-259.

SCOTT, Ana Silvia 2012. 0 caleidoscópio dos arranjos familiares. In: PINSKY, C. B. \& PEDRO, J. M. (eds.) Nova História das Mulheres no Brasil. São Paulo: Editora Contexto.

YATES, S. \& Payne, M. 2006. Not so NEET?A critique of the use of 'NEET' in setting targets for interventions with youngpeople. Journal of Youth Studies, 9, 329-344.

YATES, SCOtt; HARRIS, ANGEL; SABATES, RICARDO \& STAFF, JEREMY 2011. Early Occupational Aspirations and Fractured Transitions: A Study of Entry into 'NEET' Status in the UK. Journal of Social Policy, 40, 513-534. 